\title{
El derecho laboral en Colombia: surgimiento de una perspectiva socialista local $(1930-1945)^{*}$
}

\author{
Luz Ángela Núñez Espinel** \\ Recibido: julio de 2016 \\ Aprobado: septiembre de 2016 \\ DOI: 10.22395/ojum.v15n30a5
}

\section{RESUMEN}

Este artículo controvierte la tesis generalizada sobre el origen del derecho laboral en Colombia, que lo explica como una concesión del presidente Alfonso López al movimiento obrero por su apoyo durante el intento de golpe de 1944. Mediante un análisis histórico basado en la revisión de fuentes primarias, se argumenta que desde comienzos de la década de 1930 existieron diversas corrientes académicas y políticas que proponían desarrollar esta rama del derecho. Se profundiza en la apropiación crítica de teorías jurídicas transnacionales por los socialistas locales para poner en cuestión la supuesta insularidad y aislamiento intelectuales de la academia en Colombia y de este grupo en particular. Se concluye que el derecho laboral, entendido como derecho social por los socialistas, se nutrió de, al menos, cuatro fuentes: las corrientes antiformalistas, el materialismo dialectico y su expresión en el derecho soviético, el constitucionalismo social francés y el laboralismo inglés.

Palabras clave: derecho laboral; derecho social; Colombia; historia; trabajadores; intelectuales; legislación social; socialismo; siglo XX.

\footnotetext{
Este artículo presenta resultados parciales del proyecto de investigación "La formalidad jurídica en Colombia", desarrollado como miembro del grupo de Investigación Reforma Laboral y Mundo del Trabajo y avalado por la Universidad La Gran Colombia. Una versión preliminar del texto fue presentada como ponencia en el VII Congreso Internacional de Derecho del Trabajo y de la Seguridad Social, Bogotá, abril 20-23 de 2016.

** Licenciada en Ciencias Sociales por la Universidad Pedagógica Nacional, magíster y doctora en Historia por la Universidad de los Andes. Docente Investigadora de la Facultad de Derecho de la Universidad La Gran Colombia. Ha realizado investigaciones sobre historia intelectual, movimientos sociales y mundo del trabajo. Correo e: luz.nunez@ugc.edu.co.
} 


\section{Labor Law in Colombia: Emergence of a Local Socialist Perspective (1930-1945)}

\section{ABSTRACT}

This article challenges the general thesis on the origin of labor law in Colombia, explaining it as a concession given by president Alfonso López to the workers movement for its support during the coup d'état attempt in 1944. Through a historical analysis based on the revision of primary sources, the article states that there were several academic and political currents early in the 1930's that proposed the development of this branch of law. The article goes deeper in the critical appropriation of translational legal theories by local socialists intended to question the presumable intellectual isolation of the Colombian academicians and particularly this group. The article concludes that the labor law, understood as social right by socialists, was based at least on four sources: antiformalist currents; dialectic materialism and its expression in the Soviet law; the French social constitutionalism; and the English labor movement.

Key words: labor law; social law; Colombia; history; workers; intellectuals; social legislation; socialism; $20^{\text {th }}$ century. 


\section{INTRODUCCIÓN}

La legislación en materia laboral en Colombia hizo su aparición en la segunda década del siglo pasado y se caracterizó por ser casuística, parcial y moderada en comparación con otros países de América Latina, como Uruguay, Argentina o México. Sin que cambiara radicalmente esta realidad, puede afirmarse que a partir de 1930 se inició un segundo momento de la legislación laboral, caracterizado por un mayor intervencionismo estatal y la consolidación del Estado como árbitro de las relaciones obrero-patronales.

En 1938 se creó el Ministerio de Trabajo, Higiene y Previsión Social, pero solo hasta 1944 se expidió el Código Laboral. La reglamentación del área había sido una tarea pendiente del primer gobierno de López Pumarejo y únicamente se concretó durante su segundo mandato al amparo del estado de sitio decretado a raíz de la tentativa de golpe de Estado en julio de 1944. Las circunstancias que rodearon la expedición del Decreto 2350 de $1944^{1}$ dieron pie a diferentes lecturas políticas: como agradecimiento de López a los obreros por su respaldo durante el fallido golpe, como un intento tardío del presidente por fortalecerse ante el avance de la reacción interna o como un signo del talante socializante del régimen lopista (Triana, 2005, p. 26).

No se puede desconocer la importancia de estos acontecimientos en el campo ju-

Al año siguiente el decreto fue aprobado por el Congreso y se convirtió en Ley de la República (Ley

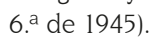

rídico, pues legitimaron desde el Estado la estructuración del derecho laboral como una rama especializada y autónoma del derecho². Sin embargo, en este artículo se argumenta que el debate público sobre la necesidad de desarrollar el derecho laboral o el derecho social en el país tenía una tradición de, al menos, tres lustros y ya había logrado algún impacto en el ámbito académico, evidenciado en la creación de cátedras y en la publicación de libros y artículos sobre el tema.

La novedad de la materia, unida a la trascendencia que se le otorgaba a la regulación de la cuestión social para la estabilidad del Estado y el progreso económico, generaron fuertes disputas durante los años treinta y cuarenta sobre la concepción y la orientación de un área del derecho que apenas estaba naciendo, como se analiza en la primera parte de este documento. En la segunda parte, se desarrolla el caso del derecho sociallaboral defendido por los socialistas locales, para poner en cuestión la supuesta insularidad y aislamiento intelectuales de la academia en Colombia y de este grupo en particular, y para analizar cómo se dio el proceso de elaboración de una teoría jurídica local a partir de la lectura y adaptación de, al menos, cuatro corrientes transnacionales.

La Ley General del trabajo fue preparada por Adán Arriaga Andrade, Ministro de trabajo en la segunda administración de López. Poco después de la expedición de la Ley se organizó la jurisdicción especial del trabajo y en 1948 —nuevamente bajo estado de sitio - se expidió el código procesal de la materia. Sobre el proceso de estructuración del derecho laboral en Colombia entre 1944 y 1949, ver los trabajos de Triana (2005, pp. 25-30) y Monsalve et al. (2014). 


\section{CORRIENTES EN PUGNA}

Como ocurre en la mayoría de los casos, la realidad antecede a la ley. Así, el avance de los conflictos obrero-patronales y de la llamada "cuestión social" durante las décadas de 1920 y 1930 propició un debate sobre cómo debería el Estado hacer frente a esta situación. En este periodo no existía ni siquiera consenso sobre la denominación, ni el ámbito del derecho al que se debían adscribir los temas laborales (público, privado, social o una nueva rama del derecho). En la mayoría de los casos, políticos y periodistas hablaban de derecho social, derecho laboral y derecho obrero como sinónimos, aunque había diferencias sustanciales entre ellos. Para los liberales más ortodoxos los temas laborales estaban circunscritos al ámbito del derecho privado, mientras que liberales de izquierda, socialistas y sectores de la Iglesia se inclinaban por la noción de derecho social, evidenciando que se trataba de un área especial del derecho donde convergían temas del derecho público y privado para atender la cuestión social. La noción de Derecho Obrero era utilizada por los sectores de izquierda para afirmar el sujeto que había dado origen al nuevo derecho, aunque reconocían que en rigor era una denominación demasiado estrecha (Molina, 1938a y Andrade, 1939).

Finalmente, se terminó imponiendo a mediados de siglo la denominación de derecho laboral como un área especializada del derecho, pero desvinculada de los problemas teóricos y políticos que planteaba el derecho social, ligazón que había sido defendida en los lustros anteriores por diferentes tendencias políticas. Iván Daniel Jaramillo (2010), uno de los pocos autores que ha estudiado las influencias jurídicas presentes en los orígenes del derecho laboral colombiano, afirma que en el primer Código Sustantivo del Trabajo están presentes las dos corrientes iuslaboralistas más importantes de la primera mitad del siglo XX: la contractualista y la de la relación de trabajo, de origen alemán. Explica Jaramillo, que "esto se debe a la influencia en los redactores de las normas del Código colombiano, de la doctrina mexicana, en cabeza del maestro Mario de la Cueva" (Jaramillo, 2010, 62).

Consideramos que, si bien la Ley 6. ${ }^{a}$ de 1945 representa un resultado hegemónico sobre lo que debía ser el derecho laboral - tanto en lo político, como en lo académico-, es necesario revisar el proceso, para comprender cuáles fueron las otras posiciones que durante los lustros previos pugnaron por un lugar dominante y dejaron alguna impronta en la academia, el movimiento sindical y el debate político³.

\footnotetext{
Nos inspiramos en la conceptualización de Florencia Mallon (2003), quien — a partir del trabajo de Gramsci- ha propuesto una forma dual de entender la hegemonía: como proceso y como resultado. En la primera, la hegemonía involucra una serie de procesos situados históricamente "a través de los cuales se legitima, redefine y disputa el poder y el significado a todos los niveles de la sociedad" (p. 85). La hegemonía como resultado sintetiza el punto de llegada de procesos hegemónicos, cuando los líderes de un determinados movimiento o coalición logran acumular suficiente apoyo o legitimidad para alcanzar un nuevo proyecto social común. Aunque dicho resultado significa la consolidación de un grupo hegemónico, éste se ve presionado a incorporar parcialmente los discursos y aspiraciones políticas de diferentes sectores (pp. 85-86).
} 
Una corriente relativamente fuerte, pero no unificada, era la que defendía la perspectiva del derecho social como marco rector para abordar los temas laborales. El elemento aglutinador era la oposición al individualismo y la comprensión de que la relación laboral no se establecía entre iguales; pero, más allá, persistían profundas divergencias ideológicas. Por ejemplo, el conservador Alfredo Vásquez Carrizosa, abogado de la Universidad de Lovaina y con vínculos con la OIT en la década de 1930, consideraba que el propósito de lograr la conciliación de las clases sociales alrededor de un Estado de tipo republicano implicaba necesariamente una reforma social y la colaboración de los sindicatos con el Estado (Vásquez,1937, pp. 799-819).

Los jesuitas, por su parte, promovieron un derecho social inspirado en el pensamiento social-católico, como reacción contra el individualismo introducido por la Revolución francesa y punta de lanza para la (re)organización corporativa de la sociedad (Figueroa y Tuta, 2005). Lo distintivo de este derecho no estaba en lo laboral propiamente, según sus promotores, sino en la expectativa de que los sindicatos y organizaciones profesionales podrían cumplir con eficacia los procesos de integración y subordinación de las personas a la sociedad, bajo una orientación moral católica, lo que permitiría que el derecho (como ordenador de la vida y la sociedad temporal) contribuyera a la preparación de la sociedad espiritual (Andrade, 1939 y Saboia de Medeiros, 1940).

En este punto se debe enfatizar que el derecho social católico estaba empa- rentado con la Acción Católica, como estrategia de la Iglesia para hacer frente a la cuestión social y a la creciente influencia de los movimientos comunistas y socialistas, pero suponía una reflexión más profunda sobre las relaciones entre el Estado, la ley, la doctrina católica y los sindicatos (Echeverri, 2009, pp. 151-182). La difusión del pensamiento social católico estuvo a cargo de la Secretaría Social de Acción Popular Católica, con una orientación fundamentalmente práctica. Pero promediando la década de 1930 la Universidad Javeriana se convirtió en el foco de irradiación de la doctrina en el ámbito académico, mediante la publicación de artículos en la Revista Javeriana y la creación de cursos de especialización sobre la materia. En 1938 la Universidad Javeriana inauguró una especialización en asuntos sociales (Curso, 1938, p. 86) y al año siguiente fundó el Centro de Estudios Sociales bajo la dirección del padre Vicente Andrade, uno de los principales exponentes de esta corriente en el país (Vida Nacional, 1939, pp. 31-32). Una década más tarde, en 1949, bajo un contexto político totalmente diferente, la Universidad Javeriana inició un curso de Especialización en Derecho Social que tenía dos secciones: una para profesores y estudiantes de Derecho, bajo la dirección del ministro de trabajo de ese entonces, Evaristo Sourdis, y otra para empleados y obreros, a cargo de Jorge Saúl Meneses, asesor jurídico de la UTC (Anaya, 1947, pp. 286-287).

El derecho social para los socialistas - como para los católicos-, también era una reacción contra el individualis- 
mo, pero se basaba en concepciones opuestas de la sociedad. Los primeros, seguidores del materialismo dialéctico se apartaban de las concepciones biologicistas y neocorporativistas que asimilaban la sociedad con un organismo biológico armónico, subyacentes en el análisis social católico, y rechazaban con fuerza las consecuencias políticas que se derivaban de dicha concepción, como la naturalización de las jerarquías sociales y el desconocimiento del conflicto social (Montaña, 1948, p. 84).

El derecho social como reacción contra el individualismo se basaba en el principio de justicia social, y su objetivo era restituir la igualdad perdida tras la falacia de la libre concurrencia en el mercado laboral. Incluía no solamente su positivación en leyes laborales, de higiene y protección social, sino que era ante todo un espíritu que debía orientar la acción del Estado para regular las relaciones de producción y dirigirlas racionalmente hacia la satisfacción de las necesidades sociales (Castel, 2010, pp. 59-75). En consecuencia, el interés en el desarrollo de una legislación social no se derivaba únicamente de una solidaridad con los trabajadores, sino que era un aspecto central del proceso de creación y distribución de riqueza. Dicho razonamiento invertía la relación entre el Estado y el sector productivo: "La obligación que pesa sobre el Estado moderno de regular las fuerzas de producción y de dirigirlas racionalmente se comprende por el fin que justifica la existencia de aquel, y que no es otro que la satisfacción de las necesidades sociales" (Molina, 1942, p. 44).
La relación entre socialismo y derecho data de mediados del siglo XIX, pero con el triunfo del fascismo esta veta de reflexión se interrumpe hasta la década de 1960, cuando — principalmente en Italia, Francia y Alemania- resurge el interés por el estudio la concepción marxista del derecho. En Colombia, en los años treinta encontramos una lectura paralela de las dos tendencias, tanto del marxismo soviético como de la tradición jurídica socialista. Dicha tradición abarca autores y escuelas del ámbito franco-alemán no necesariamente unificados alrededor de una teoría, pero que convergen en el problema de la institucionalización de la cuestión social desde una perspectiva socialista o socialdemócrata; entre ellas la corriente del socialismo jurídico, los desarrollos socialistas del concepto de derecho social y la socialdemocracia de la República de Weimar (Herrera, 2006, pp. 19-22).

\section{LA PERSPECTIVA SOCIALISTA LOCAL}

El estudio y la divulgación del derecho social con perspectiva socialista fue liderado por Gerardo Molina y Diego Montaña Cuéllar desde mediados de los años treinta con la introducción de cátedras sobre la materia en la Universidad Nacional, aunque previamente es posible localizar algunos trabajos sobre la necesidad desarrollar el derecho obrero en el país. Ejemplo de ello es el artículo de Carlos $\mathrm{H}$. Pareja, Derecho Civil y Derecho Obrero (1926), donde trata de definir las áreas de competencia de estas dos ramas del derecho y analizar en qué casos podría intervenir el derecho civil ante la inexistencia de una legislación social en el país. Poste- 
riormente, el tema estuvo presente en el programa la Liga de Acción Política, como fundamento para la reorganización de la sociedad en la posguerra y se difundió a través del periódico Acción Política, libros y artículos en revistas especializadas, como Colombia Económica y la Revista Jurídica. Además de estas vías periodísticas y académicas formales, también se divulgó a través de cursos sindicales, de la Universidad Obrera y del trabajo directo de la asesoría sindical al que estuvieron vinculados sus promotores.

Las dos obras principales sobre derecho social corresponden a manuales universitarios. El primero de ellos es Teoría general del derecho (1948), de Diego Montaña Cuéllar, y fue elaborado para la materia de Introducción al Estudio del Derecho, de la Universidad Nacional. Por esta razón, su contenido abarca mucho más que derecho social y tiene la ventaja de que nos permite profundizar en las concepciones generales del autor sobre el derecho y el lugar del área del derecho social en la materia. El otro había sido publicado una década antes y transcribe las conferencias dictadas por Gerardo Molina en la recién creada cátedra de derecho social, bajo el título Conferencias de Derecho Social (1938). En este caso, buena parte del texto está referido a aspectos técnicos y procedimentales, pero ahonda mucho más en las fuentes y las diversas corrientes del derecho social, lo que nos permite determinar la difusión y apropiación de teorías transnacionales del derecho.

En 1938 se publicó también una compilación de los trabajos presentados por los alumnos de Derecho Social al profesor Gerardo Molina, al finalizar el curso de 1937. Este trabajo es una muestra de la penetración de temas y metodologías nuevas en la universidad de la década de 1930 (Gómez, 1938). Molina fue pionero al introducir la cátedra de Derecho Social en la Universidad Nacional en 1936, pero su objetivo no era solamente "vencer algunas resistencias para conseguir que les dieran plaza a las disciplinas nacidas como expresión y reflejo del mundo del trabajo", sino transformar la concepción de la enseñanza y las metodologías tradicionales mediante la participación activa de los estudiantes en procesos de investigación sobre temas teóricos y prácticos "a efecto de que elaboren tesis y conclusiones propias, librándose así de los peligros del pensamiento dogmático" (Molina, 1938b, p. I).

Con esto queremos señalar que el debate sobre el derecho social en Colombia no puede interpretarse solamente como una forma de militancia o de respuesta/incorporación a la modernización del Estado, sino que también estaba relacionado con cambios teóricos y académico de carácter internacional, que contribuyeron a la transformación misma del derecho y su apertura hacia las ciencias sociales. Para argumentar esta afirmación, en las páginas siguientes analizamos la apropiación y/o la crítica formulada a las corrientes jurídicas antiformalistas por los socialistas locales.

Entre 1916 y 1940 se puede ubicar el período de traspaso y adaptación en nuestro país de teorías jurídicas antiformalistas 
que habían empezado a desarrollarse desde el inicio del nuevo siglo en Europa, en oposición a la escuela clásica dominante. Los esfuerzos de los juristas locales buscaban "redireccionar tanto el derecho privado como el público hacia una concepción, en general, más moderna, positivista, progresista, secular y liberal", inspirada en autores europeos de última generación. Principalmente los juristas locales siguieron los trabajos de los franceses François Gény, quien trató de construir un antiformalismo social y científico en derecho privado, y León Duguit, quien propuso una nueva orientación del derecho público (López, 2004, p. 236) .

En sus lugares de creación estas corrientes impugnaban la teoría jurídica clásica, pero en el ámbito local la doctrina dominante en la interpretación jurídica hasta comienzos de la república liberal era la doctrina del derecho natural tomista, que los juristas progresistas equipararon con la primera e hicieron blanco de sus críticas. El derecho natural era una especie de ética, definido como "aquel conjunto de principios de justicia, derivados de la ley eterna, que podemos conocer con las solas fuerzas de la razón y que son el fundamento de las demás relaciones jurídicas" (Holguín, 1929, p. 125). Como

4 El autor plantea que el producto final de este proceso es más que una copia de la teoría original. En primer lugar, las lecturas locales transforman de manera importante las teorías originales y, debido las características de la cultura jurídica nacional, se tiende a neutralizar su contenido crítico. En segundo lugar, aún en los casos en que los autores parecen dominar las teorías que están difundiendo, asumen que las premisas fácticas que las sustentan se replican en los sitios de recepción, lo que no necesariamente es cierto (p.240). se desprende de esta definición, la revelación católica es la fuente de la justicia, pero, además, sitúa a Dios como el único fundamento de la moralidad, por lo que los actos humanos deben ajustarse al orden moral impuesto por Dios. Por principio, esta escuela rechaza las teorías que prescinden de Dios como principio moral, como el utilitarismo, la escuela histórica del derecho o el evolucionismo social (Tovar, 2009, pp. 460-461).

\subsection{La crítica a Duguity Savigny desde el materialismo dialectico}

Los difusores del derecho social (socialista) colombiano reconocían el legado de las nuevas doctrinas del derecho francés y alemán porque habían resquebrajado las nociones básicas del derecho clásico (derecho natural y derecho positivo) y porque habían ampliado la concepción del Estado y de los derechos sociales. Pero seguían una posición crítica desde el materialismo dialéctico, que encontraba en ellas elementos metafísicos y contradicciones de fondo que falseaban sus fundamentos. En este sentido es interesante la crítica que Montaña Cuéllar hizo a las teorías de Savigny y Duguit, representantes, respectivamente, de la escuela histórica del derecho alemán y de la doctrina de la solidaridad e interdependencia social. Sobre la primera sentenciaba:

La historia no es lo que produce el derecho como no es lo que produce la sociedad. Es la sociedad la que hace la historia y la que produce el derecho.

La historia en sí misma no sirve para justificar el derecho, porque 
entonces tan justa sería la esclavitud como la libertad, la monogamia como la poligamia.

Hacer reposar el derecho sobre el espíritu del pueblo es hacerlos reposar sobre una ficción. Rechazando la ficción del derecho natural, la escuela histórica cae en una nueva: la conciencia jurídica del pueblo (Montaña, 1948, p. 57).

En la crítica a Duguit omitió referirse al concepto de función pública, bien conocido por Montaña Cuéllar, aunque se centró en un aspecto relacionado: la solidaridad como fundamento del derecho. Consideraba que Duguit, al igual que Savigny, partía de una ficción, porque la historia no permitía sustentar que la solidaridad fuera una ley constante en la sociedad, capaz de convertirse en fundamento del derecho. Por este camino, Montaña Cuéllar se iba aproximando a su propio argumento, al sostener que lo que demostraba la experiencia era el antagonismo de grupos y de clases. Pero antes de presentar su punto de vista, descalificaba totalmente la escuela antiformalista (aunque no utiliza esta denominación) al acusarla de caer en los mismos errores que la escuela clásica:

[...] concluir de la existencia de seres sociales, la pre-existencia de leyes sociales, es admitir que hay un orden general en el universo, y por tanto una voluntad que ha establecido este orden, lo cual es caer de lleno en la metafísica. Así, Duguit, encarnizado enemigo de la metafísica, comienza por darle al derecho un postulado metafísico (Montaña, 1948, pp. 68-69).
Montaña Cuéllar concuerda en que la fuente del derecho se encuentra en la sociedad, pero no en el ámbito de las voluntades o los sentimientos colectivos (enfoque fenoménico), sino en el proceso de producción que permite su existencia en la naturaleza (enfoque materialista). En este punto los socialistas siguen la concepción marxista del derecho difundida por la escuela soviética, basado en el Prólogo a la contribución a la crítica de la economía política de Marx y vulgarizado a través de textos de Bujarín (1919 y 1927) y Sirokov (1941).

Esta concepción del derecho se basa en la comprensión de la sociedad de manera dual, pero jerarquizada, compuesta por las relaciones de producción que actúan como la base real de la sociedad, y una superestructura condicionada por ella, donde se ubican la política, el derecho, la ciencia, la filosofía, la religión, el arte y la lengua, entre otros. El lugar del individuo en la sociedad determina su conciencia. Pero esos intereses e ideas pugnan por imponerse y solo logra mantenerse cierta forma de organización social mediante la fuerza del poder político, con su facultad de imponer el cumplimiento de determinadas normas. De allí se desprende, como consecuencia, que el derecho es la expresión de los grupos o clases más fuertes que dominan la sociedad y, por lo tanto, el fundamento del derecho hay que buscarlo en la estructura económica de la sociedad (Montaña, 1948).

En esta concepción los comunistas encuentran argumentos para desdeñar el papel del derecho en la acción política, pero los 
socialistas mantienen una visión positiva del mismo al nutrirse de otras corrientes diferentes al marxismo soviético. La primera fuente son los escritos filosóficos de Marx donde se deduce que al desaparecer la propiedad privada desaparecería la función clasista del derecho, pero que desde antes este actuaría como la conciencia de una vida nueva capaz de devolver la dignidad humana a los excluidos. O, por lo menos, esa era la lectura que Diego Montaña Cuéllar hace del "Ensayo sobre el manifiesto filosófico de la escuela del derecho histórico" de Marx (1948, p. 240 y 1996, pp. 294-295).

El énfasis se traslada del derecho como expresión de la dominación de clase, a la lucha de clases. Para ellos la legislación obrera no era resultado de la buena voluntad del Estado sino de la acción obrera mediante el sindicalismo, la huelga y otras formas de resistencia laboral. Igualmente, las leyes mismas tienen un contenido de clase y expresan la parte de la plusvalía que los capitalistas debieron ceder como resultado de la presión obrera (Molina,1936; Mújica, 1936; García, 1948; y Montaña, 1948). Con este viraje se abre la posibilidad a la existencia del derecho social como una realidad jurídica ganada por la lucha de los trabajadores, "que reposa sobre una modificación estructural de todo el pensamiento jurídico" (Mújica, 1936, p. 437).

Los difusores locales del derecho social encuentran en este una propuesta de vanguardia y con repercusiones favorables a los obreros en el campo de la política en el corto plazo, para el mejoramiento de las condiciones de vida, y en el largo plazo, para la transformación de la sociedad. En primer lugar, tienen un carácter antindividualista al desmitificar la idea de que todos los hombres son libres e iguales y analiza al hombre socializado y vinculado a una realidad en determinadas circunstancias de poder o debilidad económica o social. En segundo lugar, impone una excepción a la noción de universalidad del derecho al tratar de manera diferente a las partes y ponerse de lado del más débil. También desconoce el principio de "voluntad de las partes" que fundamenta el derecho privado, al afirmar el carácter irrenunciable de los derechos y conquistas de los trabajadores (Molina 1936 y 1939, y Mujica, 1936). Pero el carácter progresista de este derecho no se detenía allí, sino que incluía principios sobre las fuentes del derecho que rebasaban, incluso, las concepciones antiformalistas más avanzadas:

Mientras que en el código civil se considera como fuente principal a la ley, contra lo cual ha reaccionado la escuela jurídica moderna, el derecho social reconoce otras fuentes además de la ley, de la costumbre y de la jurisprudencia, y son los acuerdos o convenios habidos entre los grupos obreros y los patrones; así, el Estado les da valor jurídico a los reglamentos de fábricas, a los contratos colectivos celebrados entre los sindicatos y los patrones (Molina, 1938a, p.6).

La actividad de los obreros debía reconocerse como una fuente extra estatal del derecho social, pues se originaba y desarrollaba 
fuera del circuito de los poderes públicos. También porque había dado lugar a una transformación relativa del Estado hacia una posición intervencionista, no orientada hacia la transformación social, pero que, tras el objetivo de mantener la paz pública, había ampliado los derechos sociales (Molina, 1943).

Pero también la legislación social tenía un componente democratizador de la sociedad. Como resultado de la lucha de clases, daba a los obreros un lugar político central como creadores y veedores de la ley en la sociedad. En este mismo nivel coadyuvaba al enriquecimiento de los derechos sociales y a la limitación de algunos derechos individuales, como el derecho de propiedad, que en las nuevas constituciones aparecía limitado por el concepto de utilidad pública. Y al nivel de las fábricas erosionaba el poder despótico del patrón, imponiendo de facto una especie de democracia, gracias a la existencia misma del sindicato como contrapoder, con facultad incluso - como ocurría en Fedenal — de contratar el personal (Molina, 1938 a).

\subsection{Valoración local del constitucionalismo social y de otras fuentes socialistas}

En sus formulaciones sobre el derecho social los socialistas locales no se restringieron a reproducir la fórmula del materialismo dialéctico, sino que acudieron también a otras fuentes del socialismo y la socialdemocracia europeas, como Jean Jaurés, Harold Laski y al constitucionalismo social. Por esta vía se reforzó la visión gradualistas del socialismo, que necesariamente debía pasar por la acción del Estado y el derecho, pero ello no significó la renuncia a la lucha de clases o al recurso de la insurrección. Aunque es evidente que la mezcla del materialismo soviético con otras fuentes socialistas y social-demócratas generó cierto nivel de incoherencia, o por lo menos zonas oscuras no desarrolladas, se deben tener en cuenta dos cosas: primera, muchas de esas inconsistencias aparecen también en las fuentes europeas y remiten a grandes problemas de la teoría socialista, como es el de la transición; y segundo, ninguno de nuestros personajes construyó o aspiró a construir una teoría del derecho social; por ello, con lo que nos encontramos son reflexiones situadas desde su experiencia como profesores de Derecho y asesores sindicales, y lecturas en paralelo de algunas experiencias históricas, que fundamentan un punto de vista pero carecen de sistematización y organicidad.

Jaurés fue una figura clave en la formación política de los socialistas criollos y sirvió de inspiración para muchos de los presupuestos del derecho socialista, pese a que algunos no lo consideren como un teórico del derecho en términos estrictos. Estudios socialistas (1909) fue el libro que tuvo mayor impacto entre los círculos radicales y socialistas, aunque también se citaban otros trabajos suyos, como Discours Parlamentaires (1904), Accion socialista (1906), Pages Choisies (1928) y diversos artículos del periódico L'Humanité. De Jaurés, los socialistas tomaron una perspectiva humanista del socialismo, la 
confirmación del potencial revolucionario del proletariado y la noción de derecho social como la forma para realizar de manera gradual la idea socialista (Montaña, 1996, pp. 96-98; Acevedo 1992, pp. 383411 y Herrera, 2006, p. 44).

Como punto de partida se debe tener presente que para Jaurés el derecho era parte constitutiva del socialismo, al considerar que este había surgido en la Revolución francesa por la interacción de dos fuerzas: la idea de derecho y la acción proletaria. Pero, estas dos fuerzas también habrían dado lugar a la declaración de los derechos del hombre, por lo que el socialismo y la política de los derechos humanos estaban estrechamente relacionados, al punto que esta última servía de base a la perspectiva humanista del socialismo jauresiano y a la noción de derecho social (Herrera, 2006, p. 30).

En efecto, en la base de la noción de derecho social de Jaurés se encuentra una interpretación socialista de la declaración de los derechos humanos, que da un contenido social a la formulación —originalmente individualista - de la declaración de los derechos del hombre. El primero de los derechos es el derecho a la vida, "Pero esta formulación implicaba ya para Jaurés una extensión de la idea de derecho humano en un sentido social, una expansión que pasa por la interpretación dada a la palabra "vida", que en adelante será extendida al desarrollo de las facultades humanas" (Herrera, 2006, p.32). En este orden de ideas, el derecho social sería la realización sistemática de los derechos humanos, sobre la cual se funda la nueva sociedad, que permitiría a todas las personas su plena realización.

Los socialistas locales retomaron la perspectiva humanista que se encuentra en la base del razonamiento de Jaurés, pero no la siguieron hasta sus últimas consecuencias, al reivindicar el derecho social como derecho de clase. Para el socialista francés este postulado contradecía el principio universal del derecho que afirmaba la igualdad de todos los hombres, fueran burgueses o proletarios (Herrera, 2006, p. 34). El componente democratizador del derecho social que describimos en el parágrafo anterior también tiene una clara inspiración jauresiana. Cuando Molina afirmaba que el derecho social contribuía al enriquecimiento de los derechos sociales y a la limitación de algunos derechos individuales, como el derecho de propiedad, estaba siguiendo la lógica argumentativa de Jaurés (Molina, 1938a, p. 6 y 13).

Se podría criticar que los socialistas tenían una visión demasiado optimista de la capacidad transformadora de las instituciones jurídicas, pero, en realidad, estas eran vistas como resultado de la acción del proletariado que lograba imponer ciertos cambios en la ley o en la concepción del Estado. La nueva juridicidad podía reflejar la llegada de gobiernos progresistas o socialistas al poder, como en Alemania en la República de Weimar o en España durante la III República, pero también podía tratarse de concesiones hechas por la burguesía para tratar de contener la revolución. Sin importar cuál 
fuera el caso, el punto era que las nuevas instituciones permitían una mayor afirmación del proletariado como actor político y la construcción de un criterio socialista del Estado.

Pero, para los socialistas locales el pueblo no solamente tenía el camino de la reforma legal, sino que se reservaba para sí el derecho a la insurrección. Esta idea era común a muchas tradiciones socialistas (incluyendo la marxista) y tenía su origen en la formulación liberal de los derechos del hombre (Herrera, 2006, p. 51). La lógica que rige esta compleja relación entre la reforma legal y la rebelión no se puede buscar únicamente en el campo teórico, sino que es necesario remitirse al contexto histórico de la segunda mitad del siglo XIX europeo, donde el derecho al sufragio apareció como una de las más importantes reivindicaciones del movimiento obrero. Este implicaba una forma de igualación de los desposeídos bajo el rótulo de ciudadanos, a la cual se oponía vehementemente la aristocracia. Así, pues, el derecho a la ciudadanía, a la participación política y la reforma legal no eran para el proletariado mecanismo caducos de la política, sino derechos por conquistar. Esta misma lógica se aplicó al caso colombiano, donde el voto universal masculino se consagró apenas en la reforma constitucional de 1936; sin embargo, a diferencia del caso europeo, el proletariado era escaso y políticamente inmaduro, lo que terminaba potenciando el papel del Estado como conductor de la transformación social y constructor del ciudadano moderno (el proletario).
Esta lectura sobre la debilidad económica y política del proletariado y la mayor fortaleza del Estado, terminó potenciando el culto a la ley escrita. Por ello, pese al énfasis en el carácter extra estatal del derecho social, hubo una valoración positiva de su constitucionalización, como había ocurrido en Europa después de la primera Guerra Mundial. En este aspecto recogían el constitucionalismo social inspirado en la carta alemana de Weimar de 1919, caracterizada por el reconocimiento de los derechos laborales y de los derechos sociales asistenciales patrocinados por el Estado. La asignación del cumplimiento de estos derechos al Estado deriva de la idea de la socialdemocracia alemana según la cual el Estado (como expresión de la sociedad organizada) tiene la obligación de garantizar las condiciones para el goce de los derechos que contribuyen al desarrollo integral del ser humano (López, 2010, pp. 234-237).

Las referencias a la Constitución y al derecho social del Weimar como modelo a seguir son explícitas y reiteradas en las Conferencias de Gerardo Molina, pero los exponentes locales de las teorías del derecho social también encontraron inspiración en la Constitución mexicana de 1917 y la española de 1931. Estas cartas, desde el punto de vista de Molina, tenían una gran pertinencia para América Latina porque incluían de manera explícita el tema de los campesinos y trabajadores rurales, aspecto que había sido descuidado en las legislaciones latinoamericanas inspiradas en las fuentes alemana y francesa, que se centraban en los obreros urbanos e industriales (Molina, 1938a, 
10). Aunque con una inspiración teórica diferente, la Constitución soviética de 1918 y la legislación social implementada por la revolución fueron retomadas como ejemplo más avanzado del principio de que el Estado no solamente debía reconocer positivamente los derechos sociales y laborales sino, además, garantizar su ejercicio (Sarria, 1943).

El derecho social que originariamente tuvo un carácter nacional tendió a internacionalizarse, debido a la internacionalización de la economía y de las organizaciones de los trabajadores. Esto tomó forma en los ámbitos del derecho y la democracia internacionales con la creación de la Organización Internacional del Trabajo (OIT) en 1919, como parte del tratado de Versalles que puso fin a la I Guerra Mundial. Para el análisis político de la internacionalización del derecho laboral los socialistas locales siguieron los escritos del laborista inglés Harold Laski, quien lo analizaba como un proceso benéfico porque contenía la competencia entre naciones evitando que se deprimieran demasiado los salarios de los trabajadores. Pero para Laski el derecho internacional tenía una importancia mucho mayor que la regulación de un aspecto de la vida social. Debía ser el punto de partida de una filosofía del derecho, que superara una visión estrecha de la soberanía nacional y contribuyera a un orden de paz y justicia edificado sobre los principios socialistas (Monereo, 2005).

La impronta de Laski (1936) se encuentra en los análisis y programas políticos que formularon los socialistas para la posgue- rra, tanto en la Liga de Acción Política a comienzos de los cuarenta, como en los años siguientes. En el autor inglés encontraba en el reconocimiento a la existencia de la lucha de clases - que era un componente esencia de su identidad política-y la pretensión de la universalización un orden jurídico basado en la universalidad de los derechos y la dignidad humana. En los dos campos el derecho internacional del trabajo podía convertirse en un horizonte de sentido, pues,

\begin{abstract}
Esta pretensión de universalidad obedece a la esencia misma del derecho del trabajo, en cuya entraña late un auténtico concepto universal de justicia [...] de la que nos permitimos llamar justicia vital, o sea el derecho a conducir una existencia que corresponda a la dignidad de la persona humana. Este sentido universal de la justicia social hace que el derecho del trabajo no se conforme con las ventajas logradas en un pueblo, quiere universalizarlas porque es derecho humano (De la Cueva, 1943, p. 7).
\end{abstract}

\section{CONCLUSIONES}

Al hacer recaer la explicación de procesos socio-jurídicos complejos en la "voluntad" de un personaje, se puede llegar a una simplificación extrema, que oculta el entramado de procesos sociales y de luchas hegemónicas y contra-hegemónicas que se sitúan en su génesis. En este caso, explicar el origen del derecho laboral en Colombia, simplemente como producto de la buena voluntad del presidente Alfonso López, impide ampliar el foco 
hacia los debates políticos y académicos que desde hacía varios lustros se venían desarrollando en el país sobre la necesidad de desarrollar esta rama del derecho (aun cuando no hubiera consenso sobre el nombre).

El caso analizado nos permite concluir que, si bien la universidad colombiana de la época se caracterizaba por ser conservadora y confesional, existía cierto conocimiento de las teorías jurídicas trasnacionales en boga. Particularmente, en la Universidad Nacional algunos docentes de izquierda — de manera paralela a sus proyectos políticos personales- asumieron la tarea de disputar un lugar en el pénsum de la Facultad de Derecho para difundir algunas teorías contemporáneas de derecho social. En este proceso, la relación entre el Estado y los trabajadores se convirtió en un foco central de la reflexión, motivado por la necesidad de dar respuesta de una manera progresista al problema social que aquejaba al país. Su respuesta fue, desde los campos académico y jurídico, el desarrollo de un derecho laboral entendido como parte integral del derecho social.

Este derecho laboral se nutría de, al menos, cuatro fuentes: las corrientes antiformalistas, el materialismo dialéctico y su expresión en el derecho soviético, el constitucionalismo social francés y el laboralismo inglés. Trascendiendo la copia o la simple difusión de autores, los socialistas locales intentaron hacer una teorización propia, pero no siempre lograron articular coherentemente todas sus fuentes.
Pese a estas limitaciones, la corriente socialista pugnó, con éxito relativamente escaso, por lograr un lugar hegemónico en el campo académico y político. Sus logros iniciales, derivados de la apertura de una nueva área de estudios en la Universidad Nacional y la publicación de artículos y libros, no fueron suficientes para lograr un lugar hegemónico en la implementación del derecho laboral en Colombia. A mediados de siglo, el desarrollo legislativo y académico demuestra su reconocimiento como un área especializada, pero desvinculada de los problemas teóricos y políticos que planteaba el derecho social defendido por los socialistas.

\section{REFERENCIAS BIBLIOGRÁFICAS}

Acevedo, D. (1992). "Conversación con Gerardo Molina". En Gerardo Molina, el magisterio de la política (pp. 383-411). Bogotá: Tercer Mundo.

Anaya, R. (1949). "Crónica de la Universidad Javeriana". Revista Javeriana XXXI (155), 286287.

Andrade, V. (1939). "El contrato colectivo de trabajo". Revista Javeriana XII, (57), 76-82.

Bujarín, N. (1919). A. B. C. del comunismo. Barcelona: Editorial Clasista.

Bujarín, N. (1927). La theorie du materialisme historique. París: Editions Sociales Internacionales.

Castel, R. (2010). "El trabajo entre servidumbre y libertad: el lugar del derecho". En El ascenso de las incertidumbres. Trabajo, protecciones, estatuto del individuo (pp.59-75). Buenos Aires: Fondo de Cultura Económica,

Curso de especialización en asuntos sociales (1938). Revista Javeriana, IX (43), 86. 
De la Cueva, M. (1943). [mutilado] del derecho internacional del Trabajo. Acción Política, 6 de diciembre, p. 7.

Echeverri, S. (2009). Los jesuitas y el sindicalismo. En Rubén Sierra (ed.), República Liberal: sociedad y cultura (pp. 151-182). Bogotá: Universidad Nacional,

Figueroa, H. \& Tuta, C. (2005). El Estado corporativo colombiano: una propuesta de derechas. 1930-1953. Anuario Colombiano de Historia Social y de la Cultura (32), 99-148. Disponible en www. redalyc.org/articulo.oa?id $=127113735006$

García, A. (1948). Liberalismo y lucha de clases. Jornada, 4 de junio, p. 4,

García, A. (1951). La Democracia en la teoría y en la práctica. Bogotá: Iqueima.

García, A. (1952). El cristianismo en la teoría y en la práctica. Bogotá: Fondo de publicaciones Vicente Azuero.

Gómez, A. (1938). Balance. En Antonio Gómez (dir.), Sociología: trabajos teóricos y prácticos presentados por los alumnos de año tercero a la clase de derecho social. Bogotá, Universidad Nacional.

Herrera, C. (2006). Derecho y socialismo en el pensamiento jurídico. Bogotá: Universidad Externado de Colombia.

Holguín y Caro, H. (1929). Conferencias de Filosofía del Derecho. Revista del Colegio Mayor de Nuestra Señora del Rosario (233), 121-138.

Jaramillo, I. (2010). Presente y futuro del derecho del trabajo: breve historia jurídica del derecho del trabajo en Colombia. Opinión Jurídica 9 (18), 57-74. Disponible en http:// revistas.udem.edu.co/index.php/opinion/ article/view/74/58

Jaurés, J. (1904). Discours Parlamentaires. París: Edouart Cornely.

Jaurés, J. (1906). Acción Socialista. Barcelona: Henrick.
Jaurés, J. (1909). Estudios Socialistas. Valencia: F Sampere.

Jaurés, J. (1928). Pages Choisies. París: Editions Rieder.

Laski, H. (1936). El Estado en la teoría y en la práctica. Madrid: Editorial Revista de Derecho Privado.

López J. (2010). La constitución de Weimar y los derechos sociales. Prolegómenos XIII (26), 233243. Disponible en http://www.redalyc.org/ articulo.oa?id $=87617274014$

López, D. (2004). Teoría impura del derecho. La transformación de la cultura jurídica latinoamericana. Bogotá: Legis, Universidad de los Andes, Universidad Nacional del Colombia.

Mallon, F. (2003). Campesino y nación. La construcción de México y Perú poscoloniales. México: El Colegio de Michoacán, El Colegio de San Luis, Ciesas.

Molina, G. (1936). Criterio para el estudio de la legislación social. Revista Jurídica XXVIII (239. 240), 435-436.

Molina, G. (1938a). Conferencias de Derecho Social. Bogotá: Universidad Nacional.

Molina, G. (1938b). Explicación. En Antonio Gómez C (dir.), Sociología: trabajos teóricos y prácticos, presentados por los alumnos de año tercero a la clase de derecho social. Bogotá: Universidad Nacional.

Molina, G. (1942). Economía y política social. Colombia Económica 1 (3), 44.

Molina, G. (1943). El derecho del trabajo en Colombia, su evolución y sus características. Registro Municipal LXIII (244-248), 146-151.

Monereo, J. (2005). La democracia en crisis: Harold J. Laski. Madrid: El Viejo Topo.

Monsalve, M., Díaz, I., Gómez P., et al. (2014) Historia del Derecho del trabajo en Colombia. 
En Ángel Guillermo Ruiz Moreno (coord.), Orígenes del derecho laboral latinoamericano (pp.107-166). México: Porrúa

Montaña, D. (1948). Teoría general del derecho. Bogotá: Universidad Nacional de Colombia.

Montaña, D. (1996). Memorias. Bogotá: Universidad Nacional.

Montaña, D. (s.f). Los temas fundamentales de la filosofía del derecho. Bogotá: Los Andes.

Mújica, J. (1936). El derecho social y los trabajadores (Salvamento de voto). Revista Jurídica XXVIII (239-240), 437-439.

Pareja, C. (1926). Derecho civil y derecho obrero. Revista Jurídica 190, 346-350.

Saboia de Medeiros, R. (1940). Realidad y definición del derecho social. Revista Javeriana XIII (64), 220-230.
Sarria, E. Glosas al régimen constitucional soviético. Revista Jurídica 2 (1943), 194-199.

Shirokov, M. (1941). Tratado sistemático de filosofía. México: Ediciones Fuente Cultural, 1941.

Tovar, L. (2009). Política y derecho en las ideas filosóficas durante la República Liberal. Rubén Sierra (ed.), República Liberal: sociedad y cultura (pp. 445-482). Bogotá: Universidad Nacional.

Triana, F. (2005). Evolución del derecho del trabajo en el siglo XX. En Pedro Pablo Morcillo (ed.), Historia del derecho colombiano en la segunda mitad del siglo XX. Tomo V. Derecho social. Bogotá: Universidad Autónoma, Ediciones Jurídicas Gustavo Ibáñez.

Vásquez, A. (1937). El sindicato ante el derecho y ante el Estado. Revista Jurídica XXIX (245246), 799-819.

Vida Nacional (1939). Revista Javeriana XI (51), 31-32. 
